\title{
Parâmetros para o estudo da sinestesia na música
}

\author{
Guilherme Francisco Furtado Bragança (Coral ALMG, Belo Horizonte, MG) \\ guifrancisco@hotmail.com
}

Resumo: Estudo sobre a relação entre sinestesia como condição neurológica e a metáfora sinestésica. Propõe-se uma escuta sinestésica do $5^{\circ}$ movimento Joie du sang des étoiles de Turangalîla de Olivier Messiaen, seguida de uma análise da relação entre os elementos apontados na escuta sinestésica e a estrutura da obra. A partir desta análise e da fenomenologia, sugere-se a sistematização de categorias sinestésicas, tomando-se a sensação sonora como primária entre as sensações sinestésicas mais comuns.

Palavras-chave: sinestesia, escuta, análise musical, composição, Messiaen.

\section{Parameters for the study of synaesthesia in music}

Abstract: This paper studies the relationship between synaesthesia as a neurological condition and synaesthesic metaphor. It aims at investigating synaesthesia as a way of conscious listening and proposes a synaesthesic listening of the 5th movement Joie du sang des étoiles of Olivier Messiaen's Turangalîla, including an analysis of the relationship between the elements found in the synaesthesic listening and the structure of the work. Relating analysis and phenomenology, it also suggests a systematization of synaesthesics categories, departing from the sound as the primary sensation among the most common sensations.

Keywords: synaesthesia, listening, music analysis, composition, Messiaen.

\section{1 - Conceito de sinestesia}

No presente artigo, pretendo discorrer sobre a importância da sinestesia na escuta, análise e composição musicais, estabelecendo parâmetros gerais para o seu estudo na música. A palavra "sinestesia" deriva do grego antigo, pela justaposição da preposição syn ( $\sigma u ́ v)$, denotando união, com a palavra aisthēsis (aỉ $\sigma \theta \eta$ бı)), que significa sensação (CUNHA, 2001). A sinestesia significa o cruzamento de sensações, ou seja, a capacidade da estimulação de um sentido despertar a sensação de outro. Ela é estudada por médicos e psicólogos como um transtorno da percepção, quando esta sensação secundária se dá de forma involuntária e intensa, como uma sensação real. 0 neurologista RICHARD E. CYTOWIC (2002) menciona que o relato médico sobre sinestesia mais antigo de que se tem notícia data de 1710 , e que o primeiro trabalho que chamou a atenção da comunidade científica para o assunto foi a publicação, por Sir Francis Galton, de um artigo na revista Nature, em 1880, com o título Visualized Numerals.

De acordo com CYTOWIC (2002), há poucas referências importantes sobre sinestesia durante a maior parte do século $X X$, principalmente porque havia poucos recursos tecnológicos, exames ou testes para comprovar experimentalmente a existência dessa habilidade perceptiva incomum. Os cientistas dependiam apenas da coleta de relatos de pacientes, procedimento considerado pouco confiável para sustentar uma pesquisa empírica. Os depoimentos costumam ser imprecisos, pois muitos entrevistados se sentem inseguros em declarar que percebem algo que sabem não existir (o sinesteta tem plena consciência da realidade) e muitas vezes acabam atribuindo sua percepção à mera imaginação. Outros fantasiam suas percepções, mascarando a distinção entre a condição neurológica e a metáfora sinestésica.

Nas duas últimas décadas do século $X X$, tecnologias de imageamento cerebral, principalmente a ressonância magnética e a tomografia por emissão de pósitrons, que registram as variações do fluxo sangüíneo nas regiões do córtex em função de estímulos recebidos naquela área, ampliaram de forma significativa as pesquisas e levaram a conclusões bem mais precisas sobre a condição neurológica da sinestesia (BARON-COHEN e HARRISON, 1997, p. 5-6). Além disso, foram criados testes capazes de diagnosticar alguns tipos de sinestesia. Um teste eficaz para um tipo de sinestesia (grafema-cor) é mostrado no Ex.1, em que é apresentado um quadro com todos os numerais grafados em cinza, como o primeiro quadro abaixo (podem ser letras ou outros tipos de grafemas). 0 sinesteta grafema-cor, por enxergar cada caractere com uma cor diferente, identifica 
os numerais 2 com a mesma velocidade e acerto que uma pessoa de percepção normal e não dotada de capacidade sinestésica responderia ao ver um quadro com os numerais 2 destacados, como o segundo quadro abaixo.
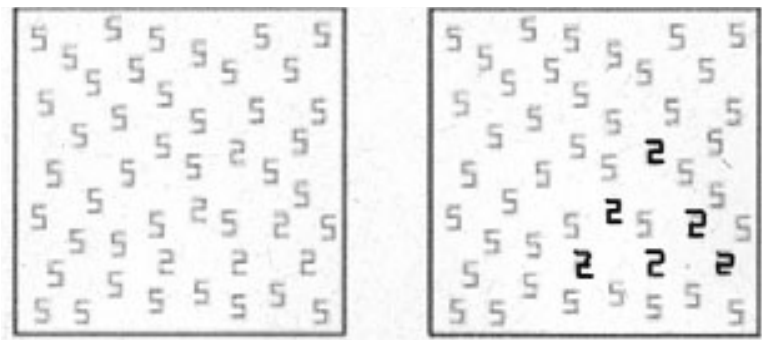

Ex.1 - Lâmina de teste para diagnosticar de sinestesia grafema-cor.

Fonte: RAMACHANDRAN; HUBBARD (2003).

Há diversos tipos de sinestesias, sendo que alguns sinestetas apresentam sinestesias múltiplas. 0 lingüista SEAN DAY (2007) enumera 54 tipos de sinestesias. 0 tipo mais freqüente é o grafema-cor, mas são muito comuns também sinestesias envolvendo sons e cores, sons musicais e cores, nomes de notas musicais e cores. São encontradas também, tendo o som como estímulo primário, as sinestesias som-movimento, som-odor, som-sabor, som-temperatura, som-tato, dentre outras. Estudos desse pesquisador apontam a audição como o sentido que mais desperta sinestesias. Segundo DAY (2007), alguns músicos e pintores possuiam, provavelmente, a sinestesia como condição neurológica, tais como Olivier Messiaen, Ligeti, Sibelius, Duke Ellington e Charles Blanc-Gatti. Outros utilizavam idéias sinestésicas em seus trabalhos, embora, possivelmente, não possuíssem essa condição neurológica. Dentre estes podemos citar Scriabin, Miles Davis, Kandinsky, Paul Klee e Mondrian.

Para o objetivo deste artigo, abordamos a sinestesia no seu sentido estilístico, de alusões voluntárias a outras percepções ao se verbalizar determinada sensação. A sinestesia como figura de linguagem é um recurso quase obrigatório ao se discorrer sobre a percepção musical, uma vez que as sensações sonoras escapam, freqüentemente, a uma definição mais objetiva. Algumas pesquisas no campo da neurologia apontam para uma proximidade entre a sinestesia congênita e a metáfora sinestésica.

Os pesquisadores da Universidade da Califórnia, V.S. RAMACHANDRAN e EDWARD M. HUBBARD (2003 p.53), afirmam que um processo semelhante à sinestesia pode ser responsável pela capacidade humana de criar metáforas e pode explicar também a atividade criativa:

Uma caracteristica compartilhada por muitas pessoas criativas é a habilidade em utilizar metáforas. É como se seus cérebros estivessem programados para fazer ligações entre domínios aparentemente dissociados. Assim como a sinestesia tece ligações arbitrárias entre entidades sensoriais como cores e números, a metáfora envolve a conexão de campos conceituais aparentemente desvinculados. Talvez isto não seja apenas coincidência.
Um experimento idealizado pelo psicólogo gestaltista Wolfgang Köhler demonstra a presença da sinestesia em todos nós, indicando ainda que estas percepções sinestésicas possam ser compartilhadas, ou seja, a maioria de nós experimentaria alguns aspectos da sinestesia de forma semelhante. 0 experimento consiste em solicitar que associemos cada uma das figuras abaixo (Ex.2), aos nomes booba ou kiki.
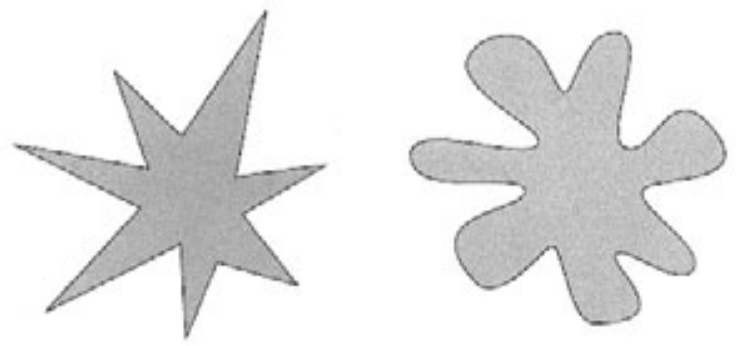

Ex.2 - 0 experimento criado pelo psicólogo Wolfgang Köhler, que consiste em associar os nomes kiki ou booba às figuras, demonstra a presença de traços de sinestesia em não-sinestetas.

Fonte: RAMACHANDRAN; HUBBARD, 2001.

Aproximadamente 95 a 98\% das pessoas escolhe kiki para a forma angular e booba para a arredondada. Segundo RAMACHANDRAN e HUBBARD (2001, p.19) a razão para esta forte convergência de resultados está na tendência a associar o desenho pontiagudo da primeira figura a uma inflexão fonética mais aguda, como em kiki, além de uma tendência maior à contração da língua contra o palato, propensões conduzidas por uma espécie de sinestesia visual-sonora-motora. Esta sinestesia do sensório para o motor explicaria também a dança, que é a imitação do ritmo ouvido em movimentos.

\section{2 - Sinestesia e significação musical}

$\mathrm{Na}$ dissertação de mestrado (BRAGANÇA, 2008), realizada sob orientação do compositor OILIAM LANNA, estabelecemos relação entre a sinestesia e a significação musical. Para chegar a tal relação, procuramos entender como se realiza o processo de significação na música. JEAN-JACQUES NATTIEZ, em seu artigo Etnomusicologia e Significações Musicais, publicado na revista Per Musi número 10 (2004a, p.6), propõe três pontos que são basilares para o entendimento da significação musical:

(...) Aquilo que denominamos "significações", quaisquer que sejam as formas simbólicas (linguagem, música, mito, cinema, pintura, etc.) em que aparecem, explicam-se semiologicamente por três princípios: todo signo é a remissão de um objeto a uma outra coisa (Santo Agostinho); o signo remete a seu objeto pelo intermédio de uma cadeia infinita de interpretantes (Peirce); estes interpretantes se repartem entre as três instâncias que caracterizam todas as práticas e as obras humanas: o nível neutro, o poiético e o estésico (Molino).

As instâncias apresentadas por JEAN MOLINO (s.d.) são dimensões de existência de um mesmo objeto simbólico. A dimensão poiética do fenômeno musical refere-se ao processo de criação, às intenções e estratégias composi- 
cionais; o nível estésico se refere ao modo como o objeto simbólico (musical) é percebido; nível neutro é o fenômeno simbólico como matéria, submetida a uma forma e pode ser comparado e categorizado no conjunto de outros objetos semelhantes. NATTIEZ propõe, ainda, que na música existem dois tipos de remissões: intrínsecas e extrínsecas. As primeiras se referem às relações formais entre estruturas musicais e é onde NATTIEZ situa o "sentido" musical", termo que o autor identifica com a sintaxe musical, um sistema de relações formais entre os constituintes de um evento musical, delineando sua estruturação. As remissões extrínsecas estão associadas à "semântica musical", na qual NATTIEZ relaciona as vinculações que o compositor (ou o executante ou o ouvinte) faz entre a música e alguma sensação, emoção, imagem, ideologia ou qualquer outra referência. Mesmo que a semântica musical seja recriada a cada momento (pelo compositor, intérprete e ouvinte), "não existe peça ou obra musical que não se ofereça à percepção sem um cortejo de remissões extrínsecas, de remissões ao mundo. Ignorá-las levaria a perder uma das dimensões semiológicas essenciais do fato musical total" (NATTIEZ, 2004a, p.7).

NATTIEZ apresenta duas posições quanto ao funcionamento das remissões extrínsecas. A primeira - reputada a LEONARD MEYER (1992), que a denomina "expressionista absolutista" - defende que as significações expressivas nascem em resposta à música, veiculadas pelo próprio significante musical. MEYER percebe relação entre as estruturas formais e algumas expectativas e respostas emocionais. A outra posição apresentada por Nattiez é de que as remissões extrínsecas existem em função de referências externas à música, ou seja, as relações entre o evento musical e as significações percebidas pelo ouvinte são construidas por convenções. NATTIEZ admite que as duas posições sejam possiveis: "existem significantes musicais que levam imediatamente a associações semânticas extrínsecas e existem aqueles que só o fazem em função de codificações convencionais". Segundo NATTIEZ, o trabalho de Meyer consiste em descrever relações entre as estruturas formais e as expectativas e realizações emocionais: "as significações musicais imanentes à matéria musical nascem da confirmação, da consolidação ou da decepção das expectativas do ouvinte" (NATTIEZ, 2004b, p.8).

LEONARD MEYER adota as leis da Gestalt descritas em seu livro Emotion and Meaning in Music (1992) como base para a compreensão das expectativas e aumento da carga emocional. Uma lei da Gestalt que MEYER considera importante para o entendimento das emoções na música é a da pregnância, que estabelece que a organização perceptiva seja a melhor que as condições prevalentes permitirem, sendo considerada boa organização a percepção que abarca condições de simplicidade, simetria, regularidade, entre outras. Outra lei da Gestalt importante no estudo de MEYER é a da boa continuidade, que é a tendência a uma forma ou padrão continuar no mesmo modo de operação se outras forças não atuarem. Tal princípio rege, por exemplo, as pro- gressões. Rege também os padrões rítmicos e métricos. Mais uma lei importante para Meyer é a da completude ou fechamento, que faz com que busquemos completar uma forma ou padrão. Tal lei nos faz, por exemplo, sentir a necessidade de conclusão de uma cadência. Outro principio é o do retorno, a tendência a voltarmos a um ponto anterior. Esta lei rege desde primitivas melodias até a macroestrutura de uma peça complexa.

A presença das leis da Gestalt confere sensação de organização à música, mas não indica a qualidade musical, pelo contrário, são os adiamentos e desvios a essas leis que geram expectativas e interesse à música, pois a correspondência às leis da Gestalt produz uma música em que o nivel de tensão e expectativa tende a zero. É central na teoria de MEYER a idéia de que as emoções são aumentadas quando a tendência de resposta é suspensa. Seu vínculo entre emoções e expectativas implica a necessidade de se conhecer o estilo, que 0 autor define da seguinte forma: "estilos musicais são sistemas mais ou menos complexos de relações sonoras entendidas e usadas por um grupo de indivíduos." (MEYER, 1992, p.45) ${ }^{2}$ Em outros termos, podemos dizer que o estilo é um conjunto de expectativas aprendidas. 0 estilo fornece as normas para que os eventos musicais possam ser considerados esperados ou surpreendentes. Para Meyer, se surge um evento inesperado, a expectativa aumenta, mas se nenhuma clarificação subseqüente da expectativa aparece, a mente rejeita todo o estímulo, que dá lugar à irritação.

Apresentamos outra abordagem, menos ligada ao conhecimento do estilo musical, para a compreensão das relações entre as estruturas formais e as remissões extrínsecas, já que podemos atribuir significações mesmo a músicas de sonoridades novas, sobre as quais não temos conhecimento prévio de seu estilo musical (BRAGANÇA, 2008). Assim, levantamos a hipótese de que existiriam dois niveis (ou dois passos) para a remissão extrínseca: o primeiro nível seria a transposição do estímulo sonoro para outras sensações, fenômeno que é definido como sinestesia no seu sentido lato, o segundo nível das remissões extrínsecas estaria relacionado ao que normalmente reconhecemos como as remissões extrínsecas propriamente: associações a sentimentos, imagens, referências, memórias, etc. A sinestesia seria um primeiro passo para a remissão extrínseca, sugerindo que as significações externas à estrutura musical passam, geralmente, por associações entre a sensação sonora e outras sensações, como visuais (brilhos, cores, claro/escuro), movimentos (direcionais, circulares, estáticos, dinâmicos), densidades (denso, rarefeito), peso (leve, pesado) ou texturas (liso, áspero). Mesmo que tais associações nem sempre cheguem a se mostrar conscientes, elas influenciariam nossa percepção. ${ }^{3}$ Um forte indicativo dessa hipótese está na terminologia que geralmente utilizamos para descrever o sonoro, recheada de termos oriundos de outras sensações, como os mencionados acima. Mesmo na descrição de estruturas musicais, ou seja, do nível imanente, recor- 
remos a termos como "texturas", "densidades", "verticalidade", etc., que são referências sinestésicas.

\section{3 - A sinestesia e o formalismo musical}

0 que propomos é tornar conscientes as percepções sinestésicas na audição, acompanhando sua condução em uma obra musical, identificar como esta sinestesia está presente como escrita musical e sugerir como idéias sinestésicas podem auxiliar no processo composicional. ${ }^{4}$ Uma abordagem de análise e composição que parte das remissões extrínsecas, particularmente das sensações, buscando relações entre elas e a sintaxe musical, parece estranha para o músico educado no formalismo do século $X X$. No entanto, tal abordagem era comum no romantismo, como defende LIAN (2005, p.1-2):

\begin{abstract}
Até meados do século XIX, além do plano expressivo, o conteúdo sentimental e evocativo da música constituia inquestionável ponto de partida para a criação sonora, destacando-se os compositores que, de uma ou outra forma, mostravam-se bem sucedidos no estabelecimento de uma comunicação emocional e intelectual com os ouvintes, sugerindo-Ihes estados de espírito, idéias e descrições a partir do discurso musical, com ou sem a concorrência de um texto verbal subjacente.
\end{abstract}

Foi nesse contexto que EDWARD HANSLICK publicou, em 1854, o livro Do Belo Musical, que contém ainda o seguinte subtítulo: Uma contribuição para a Revisão da Estética Musical. 0 objetivo do autor é fazer uma reformulação das bases da estética musical, criticando a estética do sentimento em voga e construindo um conceito de belo musical autônomo. Sua crítica se volta para a sujeição da avaliação artística aos sentimentos suscitados no ouvinte e propõe que a estética deve se voltar para o objeto de beleza (a obra) e não para o efeito, investigando os aspectos técnicos que qualificam uma música como bela. Para tal, a fruição da música deve se dar pela contemplação, um ouvir atento e com entendimento, acompanhando a movimentação das formas sonoras. 0 esteta deve retirar de seu campo de estudo tudo o que é transitório ou contingencial. HANSLICK foi o precursor de uma estética formalista, que atribui o valor da música às suas relações internas e define como seus conteúdos as interações entre os elementos constituintes da sintaxe musical.

A estética inaugurada por HANSLICK tornou-se praticamente consenso durante boa parte do séc. $X X$, influenciando a Musicologia e mesmo a composição. NATTIEZ (2004b, p.9) afirma que:

Antes de 1968, eram poucos os compositores notáveis que não tinham aderido à concepção estética da música como "forma em movimento" (...) ou à concepção semiológica da música como 'sistema autotélico', isto é, que se remete a si próprio (...). Stravinsky afirmava: A música é, por sua essência, impotente para exprimir qualquer coisa. (...) A expressão não foi jamais propriedade imanente da música. (...) Varèse: Minha música não pode exprimir outra coisa senão ela mesma. (...) Boulez: A música é uma arte não significante.

A partir de HANSLICK, considera-se mais "correto e evoluído" concentrar a escuta musical nas estruturas e suas relações (em contraposição a uma escuta "primitiva" das sensações):

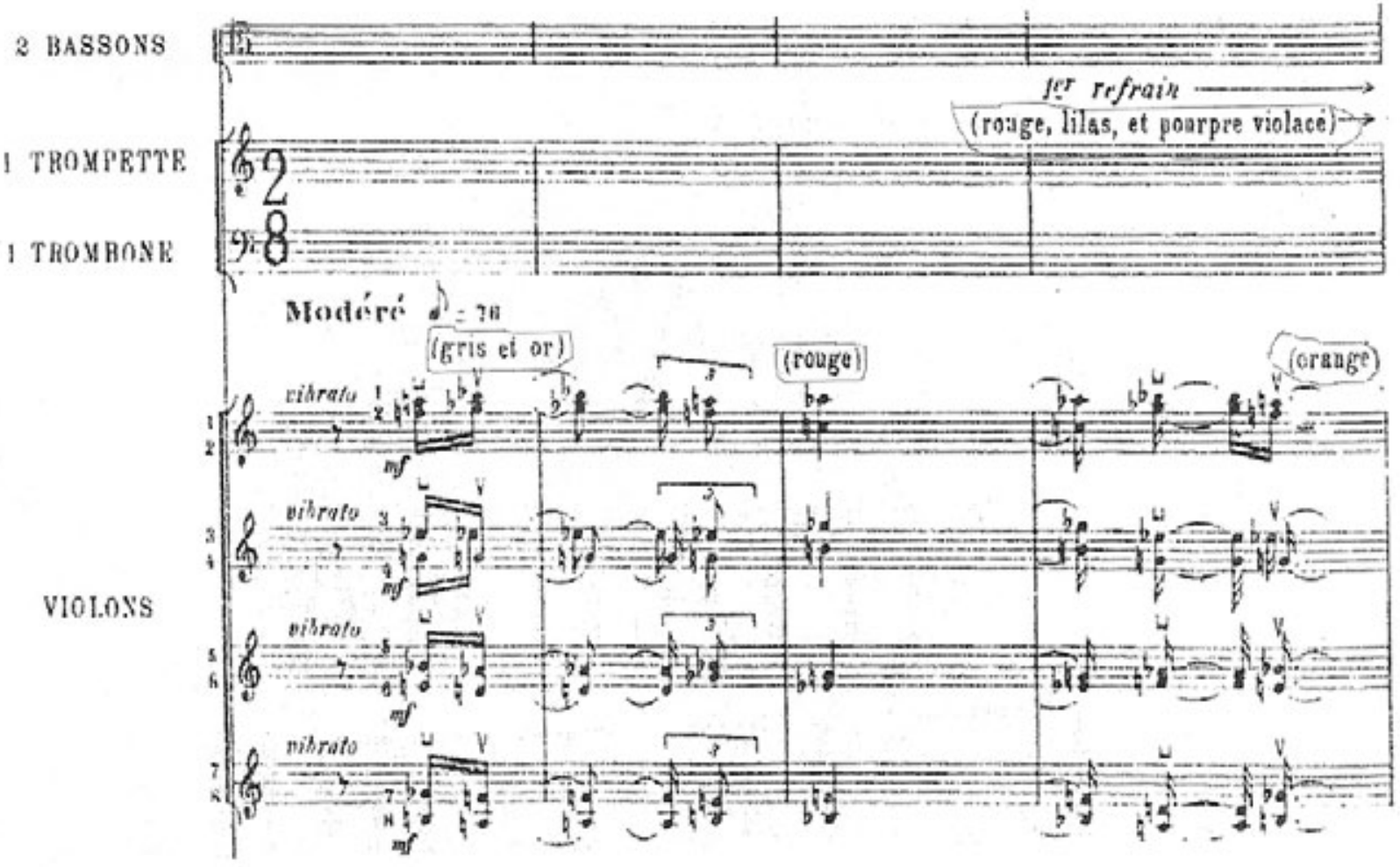

Ex.3 - Excerto de Sept Haïkaï - $n^{\circ} V_{1}$ de Olivier Messiaen. Fonte: Messiaen (1966, p.58). 
Este regalar-se de sentimento é, no mais das vezes, coisas daqueles ouvintes que não são evoluídos o bastante para a compreensão artística do belo musical. Ouvindo música, o leigo 'sente' o máximo; o artista culto, o mínimo. Ou seja, quanto mais significativo é o elemento estético junto ao ouvinte (exatamente como na obra de arte), mais indiferente se torna o efeito puramente elementar (como o autor denomina os sentimentos despertados) (HANSLICK, 1992, p.128).

HANSLICK propõe uma escuta principalmente temporal - importa acompanhar as transformações estruturais que geram a forma, atendo-se ao nivel imanente da música, sem se "desviar" em remissões extrínsecas. No entanto, não nos restringimos a esta escuta, geralmente uma música nos gera impressões, desperta sensações não sonoras, remete a imagens, idéias, lembranças. Longe de ser um problema, é em tal audição que "saboreamos" realmente uma música. Essa forma de escuta se "impõe", porque a sinestesia está constantemente presente, mesmo quando não tomamos consciência dela.

A escuta sinestésica consiste numa percepção que privilegia o instantâneo: a percepção das transposições das sensações sonoras em outras sensações. Essa forma de percepção é subestimada por estar associada a uma escuta primitiva. Apesar de sua característica eminentemente pontual, podemos "temporalizar" a escuta sinestésica, tomando consciência das sinestesias que surgem a cada momento e acompanhando como as transformações sinestésicas vão conduzindo a forma musical. Ao olharmos a música a partir da perspectiva sinestésica, percebemos que as elaborações estruturais só têm sentido e geram forma à música se têm a função de criar e transformar sinestesias. Sob este ponto de vista, uma elaboração estrutural será considerada ineficaz se não for capaz de conduzir transformações sinestésicas no ouvinte.

Como mencionei acima, é provável que OLIVIER MESSIAEN possuísse a condição neurológica da sinestesia, sendo suas obras fortemente marcadas pelas sensações visuais que eram nele despertadas. MESSIAEN estabeleceu relações entre sons e cores de forma bastante explícita em alguns textos que escreveu sobre suas obras: em Vingt Regards sur L'Enfant Jésus, para piano (1944), definiu cores para cada umas das partes, como azul-violeta para a parte V ou laranja, roxo e azul para a XIII (NAVARRO, 2008). Também na partitura dos Sept Haïkaï (Ex.3) encontramos, no $n^{\circ} V$, indicações de cores:

\section{4 - Escuta sinestésica de Turangalîla - Joie du sang des étoiles}

A Sinfonia Turangalîla, de OILIVIER MESSIAEN, é uma obra orquestral em grande escala, em dez movimentos, repleta de cores, matizes, texturas, densidades e sensações de movimentos. Ela foi escrita entre os anos de 1946 e 1948, em virtude de uma encomenda feita por Serge Koussevitzky para a Orquestra Sinfônica de Boston. Para esta encomenda, não foram estabelecidos parâmetros de duração, orquestração ou estilo, dando total liberdade ao compositor. A estréia aconteceu em 2 de dezembro de 1949, em Boston, sob a regência de Leonard Bernstein.
MESSIAEN (2008) escreve em uma nota de programa:

\begin{abstract}
Turangalîla é uma palavra em sânscrito. Como todos os vocábulos pertencentes às línguas orientais antigas, é muito rico de sentidos. Lîla significa literalmente jogo: mas jogo no sentido da ação divina sobre o cosmos, o jogo da criação, o jogo da destruição, da reconstrução, o jogo da vida e da morte. Lîla é também o Amor. Turanga: é o tempo que corre, como o cavalo à galope, é o tempo que flui, como a areia da ampulheta. Turanga: é o movimento e o ritmo; Turangalîla quer, então, dizer ao mesmo tempo: canto de amor, hino a alegria, tempos, movimento, ritmo, vida e morte. A Sinfonia Turangalîla é um canto de amor, é um hino à alegria. ${ }^{5}$
\end{abstract}

0 quinto movimento de Turangalîla tem o título Joie $d u$ sang des étoiles (Alegria do Sangue das Estrelas). Seu caráter enérgico e seus coloridos despertam no ouvinte as mais variadas sensações. Procurarei descrever uma escuta sinestésica deste movimento. Destacarei, em negrito, as principais sensações despertadas, para depois listá-las, acrescentando outras sensações. Tal listagem pode ser útil para uma futura sistematização de uma abordagem sinestésica de análise. Nesta descrição, emprego termos tradicionais de análise, como frases, semifrases, períodos, melodias e temas para dar destaque ao aspecto fortemente discursivo deste movimento da sinfonia, muito semelhante a uma conversa onde vários personagens, representados principalmente por diferentes combinações tímbricas, concordam ou discordam, reforçando ou contrapondo sensações.

Logo nos 17 segundos iniciais, ${ }^{6}$ somos capturados pelo diálogo enérgico e brilhante dos naipes orquestrais, em que percebemos frases afirmativas interrogativas, exclamativas e conclusivas. Nestas frases, "conversam" os sopros e as cordas, junto com as ondes de martenot ${ }^{7}$ em pergunta e resposta, seguidas por um comentário de piano e sopros mais cordas, e, por último o piano numa escala ascendente e tutti numa escala descendente pontuam a "conversa". Este trecho é bastante simétrico, direcional e conclusivo, sendo logo repetido com uma clareza clássica. A direcionalidade é reforçada principalmente pela relação dominante tônica das frases, mas também pela regularidade rítmica. Além do andamento vivo e da energia do ritmo, as constantes mudanças de timbre reforçam a sensação de movimentação. 0 calor e o brilho parecem estar muito presentes neste trecho. As frases musicais parecem soltar "faíscas", pela presença do prato em cada uma delas. Este trecho, com sua repetição, expõe 0 primeiro tema e dura, ao todo, 34 segundos.

A seguir, inicia-se uma dança, em que os motivos se alternam rapidamente nos metais e nas cordas. A frase termina como um desenho mais circular do piano, celesta, madeiras e cordas. Esta frase é logo repetida. A sensação de simetria continua neste trecho: os motivos angulares nos metais e cordas têm o mesmo número de tempos que o desenho circular do piano. Logo em seguida é a vez da alternância entre madeiras e metais, que funciona como uma "quase imitação", na forma de pequenos arranques, também repetidos. Há uma pontuação de pandeiros, com o cintilar das pratinelas. Segue um motivo ondulante nas 
trompas. Este trecho contrasta-se com o primeiro, por não ser tonal, mais anguloso e menos direcional.

Uma grande escala ascendente em crescendo faz emergir novamente o primeiro tema, após cerca de 50 segundos de música. Esta reexposição do tema acontece num "ambiente" mais agitado, porque o piano e a celesta fazem um movimento contínuo e rápido, num sobe e desce que fica ao fundo do tema. 0 segundo tema também é apresentado com modificações. Há um peso maior, pela presença do bombo pontuando a primeira frase. Alguns motivos em notas rápidas são substituídos por notas um pouco mais longas em crescendo, gerando uma tensão que se represa e cresce. Há o tema ondulante nas trompas e a escala ascendente, fazendo ressurgir, com 1 minutos e 27 segundos de música, o início do primeiro tema, mas apenas para iniciar uma seção de finalização dessa seção. Aqui temos a primeira semi-frase do tema, repetida em progressão, a escala descente da orquestra junto com um movimento ascendente no piano, motivos angulares, motivos não tonais justapostos ao acorde de tônica, mesclando, assim elementos do primeiro e do segundo temas. 0 movimento contínuo do piano e das cordas no final dessa seção conduz toda a energia para a finalização num acorde de tônica, pontuado pelo tamtam. Há também uma aceleração no pandeiro que acumula energia para o final.

Após um minuto e 50 segundos de música, há a maior articulação até o momento, iniciando a segunda grande parte do movimento. Esta seção contrasta muito com a primeira pelo caráter muito mais desordenado. 0 piano é tocado freneticamente, enquanto os instrumentos da orquestra fazem motivos que parecem ser tirados dos temas iniciais, mas soltos na massa sonora. A sensação é de discussão acirrada entre os instrumentos, surgindo, por algumas vezes, gemidos dos glissandi das ondes de martenot. 0 piano, junto com as cordas graves, produz sons semelhantes a trovões.

Apesar de haver muitos sons agudos soando todo o tempo (a celesta parece tocar quase continuamente nesta seção), não há o brilho alegre anterior, pelo contrário, a alternância muito próxima de agudos e graves gera tensão e angústia. Aos 2 minutos e 26 segundos de música há um leve afrouxamento da densidade sonora e surge nas ondes de martenot e nas cordas, dois fragmentos do primeiro tema. Logo após, três fragmentos do primeiro tema aparecem mais fortes, principalmente nos metais. Voltam os graves, com a intervenção do bombo, e então aparece, aos 2 minutos e 47 segundos, um fragmento do segundo tema. Há uma aceleração e voltam a se instalar a tensão e o caos, com muitos elementos semelhantes aos momentos que antecedem o ressurgimento do primeiro tema. Novamente, há um relaxamento da densidade e um fragmento do primeiro tema surge nas ondes de maternot, aos 3 minutos e 30 segundos. Ele aparece outra vez nas ondes de maternot e mais duas vezes nos metais e madeiras. Outros elementos do primeiro e segundo temas aparecem, como o motivo ondulante das trompas, que se estende para o restante da orquestra e acumula tensão para preparar a reexposição.

Aos 4 minutos e 14 segundos, o primeiro tema é reexposto no mesmo "ambiente" mais agitado que aconteceu aquela exposição do quinqüagésimo segundo de música. Apenas o primeiro tema é apresentado. Em seguida, há uma parte muito semelhante à finalização da primeira parte da música, mas que se estende, surgindo dois grandes glissandi das ondes de maternot, que dialogam com os trombones, numa retenção do fluxo. Temos, então, uma interrupção do tempo, para a realização de uma cadência de piano. Após um ruflar do bombo, toda a orquestra toca acordes finais, sendo o último mais longo, num crescendo que despeja, fulgurante, toda a energia da orquestra.

Dentre as palavras destacadas, a maioria conota sensações sinestésicas (sensações não-sonoras despertadas pelo evento sonoro). Outras, como a palavra angústia, situam-se no campo dos sentimentos, relacionando-se ao segundo nivel de remissão extrínseca que apresentamos, provavelmente porque o primeiro nível de remissão, o das sensações físicas, permaneceu inconsciente. Neste artigo, vamos nos limitar às sensações sinestésicas.

\section{5 - A sinestesia na análise e composição}

A análise sinestésica consiste em procurar entender como as estruturas se relacionam com as sensações sinestésicas e como as transformações estruturais modificam as sinestesias e geram a forma musical. ${ }^{8}$ Não se pretende, na análise sinestésica, construir uma relação única de causa e efeito entre sensações e estruturas. Certamente há outras sinestesias possíveis para esta música e as descritas podem ser despertadas por eventos sonoros diversos do que poderiam ser encontrados numa análise. Estamos aqui num campo de tendências e possibilidades, não de leis composicionais. Por outro lado, acreditamos ser possível mapear relações entre 0 nível neutro e o estésico, o que parece ser algo bastante óbvio, já que o oposto seria conceber que qualquer estrutura poderia despertar qualquer sensação e as escolhas composicionais não teriam qualquer repercussão no resultado musical.

A análise a partir da sinestesia pode ser entendida como um ramo da abordagem fenomenológica da análise musical. A fenomenologia retoma a questão da relação entre sujeito e objeto, fazendo frente à visão positivista, que considera reais somente os conhecimentos resultantes de fatos observados. Esta corrente de pensamento postula que a verdade é encontrada quando um sujeito observa com neutralidade o mundo externo, munido de rigoroso método científico. Apresenta-se, assim, uma dicotomia entre sujeito e objeto, na qual o mundo externo existe como uma verdade independente, à espera de um sujeito que, de fora desse mundo, decifre suas leis fundamentais. 0 positivismo manifesta-se no estudo musicológico quando se isola uma partitura da percepção musical e de todo 
o contexto, para estudá-la com uma minuciosa metodologia de análise, descobrindo suas leis composicionais.

A palavra "fenômeno" deriva do grego phainómenon, significando "tudo que é percebido pelos sentidos ou pela consciência" (CUNHA, 2007, p. 353). A fenomenologia estuda o objeto não como algo independente, mas como um fenômeno, aquilo que se apresenta à consciência. Esta, por sua vez, não é um ente abstrato, mas consciência de algo. Supera-se, assim, a dicotomia sujeito-objeto: o mundo da fenomenologia é o mundo experienciado por uma consciência que sempre visa algo, tem uma intencionalidade. Essa intencionalidade da consciência doa sentido ao mundo.

A palavra intencionalidade não significa outra coisa senão essa caracteristica geral da consciência de ser consciência de alguma coisa, de implicar, na sua qualidade de cogito, o seu cogitatum em si mesmo (HUSSERL, apud COELHO JÚNIOR, 2002).

Para a fenomenologia não há por que estudar a música como um conjunto de elementos que se organizam numa sintaxe. A música existe como um fenômeno que se apresenta para um ouvinte e é a partir desta instância que ela é investigada. Uma análise fenomenológica não terá a finalidade de explicar a música ou dela derivar leis fundamentais, mas procurará descrever a vivência do fenômeno musical. Nas palavras de KOELLREUTTER (1989, p.1):

\footnotetext{
A análise fenomenológica não visa uma explicação teórica da obra, mas sim, exclusivamente, uma interpretação da mesma, apontando um único objetivo: o de vivenciar as idéias musicais e de conscientizá-las de acordo com o entendimento teróricomusical e estilistico, conforme o grau de sensibilidade de quem a analisa.
}

A composição a partir da perspectiva sinestésica sustenta-se, como a análise sinestésica, na hipótese apresentada anteriormente de que as remissões extrínsecas são de dois níveis: o primeiro de remissões sinestésicas e o segundo de evocações externas ao fenômeno musical. Estes niveis atuariam como dois "passos" da remissão extrínseca. Dessa forma, uma música (sensação sonora) desperta outras sensações (visuais, cinéticas, táteis, etc.) que podem evocar uma imagem, um poema, uma vivência pessoal, etc.

No processo composicional pode acontecer o mesmo (em ordem inversa): um poema, um programa ou lembranças despertariam sensações (de claro e escuro, direcionamento ou circularidade, por exemplo) que seriam transpostas para eventos musicais. 0 segundo nível de remissões extrínsecas realiza-se não só na criação, mas refaz-se a cada interpretação e audição de forma idiossincrática, ou seja, compositor, intérprete e ouvinte fazem remissões extrínsecas de segundo nível a partir de suas histórias pessoais. Já o primeiro nível de remissões extrínsecas, de relações sinestésicas, é relativamente compartilhado, pelo menos numa mesma época e cultura, cabendo até a criação de um sistema de classificação: seria possível relacionar objetos sonoros a sensações sinestésicas que estes despertam.

A primeira contribuição que podemos dar para a composição a partir da perspectiva sinestésica seria a elaboração de um sistema de classificação que relacionaria procedimentos e objetos sonoros a resultados sinestésicos possiveis de serem despertados. É claro que não pretendemos construir um sistema fechado, em que somente um determinado procedimento conduziria a apenas um tipo de sinestesia, mas categorias de possibilidades sinestésicas. Categorias mais amplas e gerais seriam mais objetivas (mais consensuais, porém menos interessantes musicalmente), já categorias mais sutis e musicais teriam maior grau de subjetividade. Por exemplo, podemos classificar eventos musicais em grandes categorias sinestésicas como "brilhante" e "escuro" ou então "denso" e "rarefeito". No entanto, existem muitas formas e gradações de "brilho" sonoro ou de "densidades", existem inúmeras combinações sinestésicas (brilhos, densidades, texturas, movimentos) nas mais variadas gradações, podendo haver ainda variadas formas e velocidades de transformações de uma sinestesia em outra. A maestria composicional, do ponto de vista sinestésico, significa o domínio dessas formas, gradações, combinações e transformações que tornam a música menos óbvia e muito mais rica.

A sistematização de categorias sinestésicas é uma tarefa longa, não sendo possível desenvolvê-la no âmbito de um artigo. Pretendemos aqui apenas lançar a proposição de tal sistematização. Um caminho para isso seria distinguir pólos de sensações secundárias (sinestésicas) despertadas pela sensação sonora. Assim, na categoria de sinestesia visual teríamos procedimentos de matizes - do claro ao escuro. Podemos ter também categorias de cores. As relações entre cores e elementos musicais têm geralmente um grau muito alto de subjetividade, mas podemos perceber uma tendência geral de cores de faixa de freqüência mais baixa (próximas ao vermelho) serem despertas por elementos musicais mais agitados, densos e "quentes". Ao contrário, elementos musicais mais calmos, rarefeitos e "frios" tendem a associar-se a cores de freqüências mais altas (como o azul ou violeta).

Além de cores e matizes, são muito comuns na descrição de eventos musicais o emprego de referências a densidade, pressão, movimento, calor e textura (como sensação de superfície e como trama). Em cada uma destas sensações, podemos encontrar, pelo menos, dois pólos opostos, que são, geralmente, extremos de um contínuo de possibilidades. Podemos construir a tabela abaixo (Ex.4), incluindo algumas sensações descritas na escuta de $T u-$ rangalîla, além de outras: 


\begin{tabular}{|c|c|c|c|}
\hline Sensação secundária & \multicolumn{3}{|c|}{ Pólos opostos } \\
\hline \multirow[t]{2}{*}{ Brilho } & \multicolumn{2}{|l|}{ Claro } & Escuro \\
\hline & \multicolumn{2}{|c|}{ Brilhante (fulgurante) } & Apagado, sombrio \\
\hline Transparência & \multicolumn{2}{|c|}{ Transparente } & Opaco \\
\hline Cores & \multicolumn{2}{|c|}{ Violeta } & Vermelho \\
\hline Densidade & \multicolumn{2}{|l|}{ Rarefeito } & Denso \\
\hline Energia & \multicolumn{2}{|l|}{ Débil } & Enérgico \\
\hline \multirow{2}{*}{ Espaço } & \multicolumn{2}{|l|}{ Figura } & Fundo \\
\hline & \multicolumn{2}{|l|}{ Amplo } & Constrito \\
\hline Pressão & \multicolumn{2}{|l|}{ Leve } & Pesado \\
\hline \multirow{7}{*}{ Movimento } & \multicolumn{2}{|c|}{ Não-direcional } & Direcional \\
\hline & \multicolumn{2}{|c|}{ Acelerado } & Retardado \\
\hline & \multicolumn{2}{|c|}{ Crescer } & Decrescer \\
\hline & Circular & Angular & Linear \\
\hline & \multicolumn{2}{|l|}{ Subir } & Descer \\
\hline & \multicolumn{2}{|l|}{ Calmo } & Agitado \\
\hline & \multicolumn{2}{|l|}{ Lento } & Rápido \\
\hline \multirow{2}{*}{ Ordenação } & \multicolumn{2}{|l|}{ Regular } & Irregular (caótico) \\
\hline & \multicolumn{2}{|l|}{ Simétrica } & Assimétrica \\
\hline Temperatura & \multicolumn{2}{|l|}{ Frio } & Quente \\
\hline Textura - superfície & \multicolumn{2}{|l|}{ Liso } & Áspero \\
\hline Textura - trama & \multicolumn{2}{|l|}{ Unilinear } & Intrincada \\
\hline
\end{tabular}

Ex.4 - Sensações secundárias que comumente decorrem da audição musical e os pólos opostos de cada uma delas.

\section{6 - Conclusão}

Algumas qualidades sinestésicas são intercambiáveis, ou seja, um mesmo trecho musical pode ser percebido como transparente, numa sinestesia visual, ou leve, numa referência tátil de pressão, ou gélido, pela sinestesia tátil de calor. Os parâmetros sonoros contribuem de forma conjunta, porém, muitas vezes, com pesos diferentes, na produção de uma sinestesia. Assim, uma sinestesia de movimento como a percepção de agitação em trecho musical tem uma forte contribuição do parâmetro rítmico, mas pode ser reforçado por determinado timbre ou registro. Uma sensação de leveza pode ser construída pela combinação de parâmetros de intensidade, timbre, registro e rítmica.

A sinestesia tem uma aplicação direta na análise fenomenológica da música, ao criar as bases para uma metodologia de análise musical a partir da percepção sinestésica da música e da compreensão das construções que condicionam tais percepções. A abordagem sinestésica pode ainda auxiliar o estudante de composição a relacionar determinados resultados sonoros (sinestésicos) a determinados sistemas de construção musical. 


\section{Referências:}

BARON-COHEN, S., HARRISON, J. (Eds) Synaesthesia: Classic and Contemporary Readings. Oxford:Blackwell Publishers Itd, 1997.

BRAGANÇA, Guilherme Francisco Furtado. A sinestesia e a construção de significação musical. Dissertação (mestrado) Universidade Federal de Minas Gerais, Escola de Música, 2008.

COELHO JÚNIOR, Nelson Ernesto. Consciência, intencionalidade e intercorporeidade. Revista Cadernos de Psicologia e Educação Paidéia. Ribeirão Preto, v.12, n.22, 2002.

CUNHA, Antônio Geraldo da. Dicionário etimológico Nova Fronteira da língua portuguesa. Rio de Janeiro: Nova Fronteira, 1997.

CYTOWIC, Richard E. Touching tastes, seeing smells - and shaking up brain science. Cerebrum, v.4,n.3: p.7-26, 2002. (artigo hospedado em http://home.comcast.net/ sean.day/CytowicCerebrum2002.pdf)

DAY, Sean. Lafayette (USA). Julho, 1996. Disponivel em: http://psyche.cs.monash.edu.au/v2/psyche-2-32-day.html, acessado em 09/10/2006.

DAY, Sean. Synesthesia: the American Synesthesia Association. Disponivel em: http://home.comcast.net/ sean.day/Synesthesia.htm, acessado em 01/05/2007.

GAZZANICA, Michael S; HEATHERTON, Todd F. Ciência psicológica: mente, cérebro e comportamento. VERONESE, Maria Adriana Veríssimo (trad). Porto Alegre: Artmed, 2005.

HANSLICK, Eduard. Do belo musical: uma contribuição para a revisão da estética musical. Nicolino Simone Neto (trad). Campinas: Editora da UNICAMP, 1992.

KERMAN, Joseph. Musicologia. CABRAL, Álvaro (trad). São Paulo: Martins Fontes, 1987.

KOELLREUTTER, H.J. Análise Fenomenológica do minueto em sol maior de J.S. Bach. Cadernos de análise Musical. São Paulo: Atravez, n.1: p.1-8, 1989.

LIAN, Henrique. Sinfonia Titã: semântica e retórica. São Paulo: Perspectiva, 2005.

MESSIAEN, Olivier. Sept Haïkaï: esquisses japonaises pour piano solo et petit orchestre. Paris, Alphonse Leduc, 1966.

MESSIAEN, Olivier. Turangalila - 05 - Joie du sang des étoiles. Loriods, Ozawa, Boston SO, Tanglewood 1975

MESSIAEN, Olivier. Turangalîla-Synphonie, in Philharmonia Orchestra's Messiaen website, disponivel em: http://www. philharmonia.co.uk/messiaen/music/turangalila.html, acessado em 20/04/2008.

MESSIAEN, Olivier. Turangalîla-Synphonie, note de programme. Disponivel em: http://www.messiaen2008.com/fiche. php?id $=24$, acessado em 25/04/2008.

MESSIAEN, Olivier. Turangalîla Symphonie, 5th Movt "Joy of the Blood of the Stars". Pierre Laurent Aimard, Cynthia Millar, Andrew Davis, and the National Youth Orchestra of Great Britain at the 2001 Proms. Disponivel em: http://br.youtube. com/watch?v=Tv67YkOWJNA, acessado em 25/04/2008.

MEYER, Leonard B. Emotion and meaning in music. Chicago, The University of Chicago Press, 1992.

MOLINO, Jean. Fato musical e semiologia da música. In: Semiologia da música. CARVALHO, Mário Vieira (trad). Lisboa: Vega, s.d.

NATTIEZ, Jean-Jacques. Situação da Semiologia Musical. In: Semiologia da música. CARVALHO, Mário Vieira de Carvalho (trad). Lisboa: Vega, s.d.

NATTIEZ, Jean-Jacques. Som/ruido. In: Enciclopédia Einaudi. Artes-Tonal/Atonal. Lisboa: Imprensa Nacional - Casa da Moeda, v.3: p.212-228, 1984.

NATTIEZ, Jean-Jacques. Musi and discource: toward a semiology of music. Carolyn Abbate (trad para o ingles). Princenton, New Jersey, Princeton University Press, 1990.

NATTIEZ, Jean-Jacques. Etnomusicologia e significações musicais. Silvana Zilli Bomskov (trad). Per Musi, Belo Horizonte, n.10: p.5-30, 2004a.

NATTIEZ, Jean-Jacques. Modelos lingüisticos e análise das estruturas musicais. Sandra Loureiro de Freitas Reis (trad). Per Musi, Belo Horizonte, n.9: p.5-46, 2004 b.

NATIIEZ, Jean-Jacques. 0 combate entre Cronos e Orfeu: ensaios de semiologia musical aplicada. São Paulo: Via Lettera editora e livraria, 2005.

NAVARRO, Daniel Pérez. Escucho los colores, veo la música: sinestesias. El compositor sinestésico: Olivier Messiaen. Disponível em: http://www.filomusica.com/filo48/sinestesia.html, acessado em 30/04/2008.

RAMACHANDRAN, Vilayanur S.; HUBBARD, Edward M. Synaesthesia: a window into perception, thought and language. Journal of Consciousness Studies, v.8, n.12, p.3-34, December 2001.

RAMACHANDRAN, Vilayanur S.; HUBBARD, Edward M. Ouvindo as cores e degustando as formas. Scientific American. São Paulo, n.13, Junho de 2003.

SYNESTHESIA. In: Wikipedia, the free encyclopedia. Disponivel em: http://en.wikipedia.org/wiki/Synesthesia. Acessado em: 01/05/2008. 


\section{Notas}

1 A palavra"sentido" tem muitos empregos e é por demais corriqueira para que seja reservada apenas a um significado definido por determinado autor. Assim, tal palavra continuará sendo utilizada no texto em seus múltiplos significados comuns, aparecendo entre aspas na expressão "sentido musical" quando designar, como faz Nattiez, a sintaxe musical.

2 Musical Styles are more or less complex systems of sound relationships understood and used in common by a group of individuals.

3 Em 1953, o psicólogo britânico E. C. CHERRY estudou um processo de audição seletiva que denominou "fenômeno da festa de coquetel", que consiste na capacidade de focar em uma conversa no meio de várias outras, mesmo que a conversa focada não seja a de maior intensidade. Em 1958, o psicólogo DONALD BROADBENT desenvolveu estudos relacionados ao foco da atenção, criando a teoria do filtro de que temos uma capacidade limitada de apreender informações sensoriais, selecionando as que julgamos mais importantes. Teorias posteriores postularam que a audição seletiva não é um processo tudo-ou-nada, mas opera por múltiplos estágios onde algumas informações são filtradas, não chegando à consciência, embora possam alterar a percepção final. (GAZZANIGA; HEARTHERTON, 2005).

4 Na dissertação de mestrado, discorro sobre a relação entre a sinestesia e as três dimensões de existência do objeto simbólico, definidas por Molino: dimensões estésica, neutra e poiética.

5 Tradução do autor do texto original em francês: Turangalîla est un mot sanskrit. Comme tous les vocables appartenant aux langues orientales antiques, il est très riche de sens. Lîla signifie littéralement le jeu : mais le jeu dans le sens de l'action divine sur le cosmos, le jeu de la création, le jeu de la destruction, de la reconstruction, le jeu de la vie et de la mort. Lîla est aussi l'Amour. Turanga : c'est le temps qui court, comme le cheval au galop, c'est le temps qui coule, comme le sable du sablier. Turanga : c'est le mouvement et le rythme; Turangalîla veut donc dire tout à la fois : chant d'amour, hymne à la joie, temps, mouvement, rythme, vie et mort. Turangalîla-Symphonie est un chant d'amour. Turangalîla-Symphonie est un hymne à la joie.

6 Como referência para a descrição realizada neste trabalho, utilizei duas gravações: 1) Messiaen - Turangalila - 05 - Joie du sang des étoiles - Jeanne Loriod e Seiji Ozawa, Boston SO, Tanglewood 1975. 2) Messiaen's Turangalîla Symphonie, 5th Movt "Joy of the Blood of the Stars". Pierre Laurent Aimard, Cynthia Millar, Andrew Davis, and the National Youth Orchestra of Great Britain at the 2001 Proms. (disponivel no Youtube). A minutagem foi realizada a partir desta última referência. Nela, há 13 segundos antes do início da música, que foram descontados.

7 É um dos primeiros instrumentos musicais eletrônicos (o primeiro foi o Theremin), inventado em 1928 por Maurice Martenot, que produz sons por meio de um teclado que controla freqüências de um oscilador. As capacidades do instrumento sonoro foram posteriormente ampliadas por meio da adição de controles de timbres e alto-falantes comutáveis. Produz apenas um som de cada vez, de freqüência ondulante, sendo também, capaz de produzir glissandi.

8 No presente artigo restringimo-nos à descrição de uma escuta sinestésica, sem recorrer à partitura da obra. Para ver um exemplo de análise sinestésica, consulte o trabalho A sinestesia e a construção de significação musical (BRAGANÇA, 2008) onde, além de relatar a escuta da música Baku Pari, de Guilherme Nascimento, dentro de uma perspectiva sinestésica, realizamos a análise daquela música a partir das sinestesias percebidas.

Guilherme Francisco Furtado Bragança graduou-se em Composição pela UFMG (1989), concluiu os cursos de Pós-Graduação Lato-Sensu para o Magistério Superior pela FUMA (1990) e "Musicologia Histórica Brasileira", pela UFMG (1994). Estudou regência coral com Carlos Alberto Pinto Coelho e Hans Joachin Koellreuter. Em 2008, concluiu o mestrado em Música pela UFMG. Lecionou, por dois anos, no curso superior de música da UEMG as matérias Acústica e Música Contemporânea e para o curso básico, Harmonia I e II. Atualmente, rege o Coral da Assembléia Legislativa de Minas Gerais. 